\title{
Qualitative Studies on Chhana Prepared from Cow and Buffalo Milk
}

\author{
Sarfraz Ahmed ${ }^{1}$, Dilpat Rai Menghwar ${ }^{2 *}$, Ubaid Qureshi ${ }^{1}$, Tanveer Ahmed ${ }^{1}$, Salahuddin Jakhrani ${ }^{1}$ \\ ${ }^{1}$ Department of Animal Products Technology, Faculty of Animal Husbandry and Veterinary Sciences, Sindh Agriculture University \\ Tandojam, Pakistan \\ ${ }^{2}$ Department of Animal Sciences Faculty of Biological Sciences, Quaid-i-Azam University Islamabad, Pakistan
}

\begin{tabular}{l}
\hline A R T I C L E I N F O \\
Research Article \\
Received 20 March 2018 \\
Accepted 18 May 2018 \\
\hline
\end{tabular}

Keywords:

Acetic Acid

Buffalo milk

Chhana

Citric acid

Cow milk

Lactic acid

\begin{abstract}
A B S T R A C T
Qualitative studies on chhana were carried out at Sindh Agriculture University Tandojam during the year 2011-12. Two milk sources (i.e. cow milk and buffalo milk) and three coagulants (i.e. acetic acid, citric acid and lactic acid) were used during the study period. Physical characteristics such as titratable acidity and $\mathrm{pH}$ values. Preliminary, the chhana was prepared from each of cow and buffalo milk coagulated with acetic acid, citric acid, and/or lactic acid each at 0.5, 1, 2 and 4\% concentration level. Among each coagulant, concentration level showed significant influence on the acceptability score of chhana. Product made with $0.5 \%$ concentration level perceived the better acceptability (score). A remarkable influence of milk source was observed in $\mathrm{pH}$ values of chhana prepared from cow milk and buffalo milk either with acetic acid (5.65 \pm 0.01 and $5.45 \pm 0.01$, respectively) or with citric acid (5.52 \pm 0.02 and $5.45 \pm 0.01$, respectively). In this study, buffalo milk chhana was found better in all aspects compared to that of cow milk.
\end{abstract}

$\frac{\text { *Corresponding Author: }}{\text { E-mail: rai48_sau@yahoo.com }}$

DOI: https://doi.org/10.24925/turjaf.v6i7.936-939.1925

\section{Introduction}

Chhana, an Indian counter part of soft cheese is a heatacid coagulated product of milk. It is prepared by precipitating the whole milk of cow or buffalo or a combination thereof by boiling and adding of lactic acid, citric acid or any other suitable coagulating agent, and subsequent drainage of whey (Sahu and Das, 2009). Traditionally, the chhana is prepared by heating the milk to its boiling point in open pan and allowed to cool in between 75 to $80^{\circ} \mathrm{C}$ by constant stirring. Thereafter 1 to $2 \%$ of acid coagulant has been added to it. During the coagulation process, the milk and acid solution is stirred slowly with the help of ladle, and continued until the milk gets precipitated and settled down at the bottom of the pan. The clear whey floating on the top is filtered through a muslin cloth and semi solid curd is collected for the consumption. Chhana being a rich source of fat and protein, fat-soluble vitamins $\mathrm{A}$ and $\mathrm{D}$, and low sugar content is highly recommended for the diabetic patients (De, 1980). It has been reported that factors like type of milk, heat treatment given to milk prior to acidification, coagulation temperature, acidity of milk-acid mixture and residence time of the coagulated chhana-whey mixture before separation of milk solids from whey may influence the yield and chemical composition of chhana. Processing factors like type of coagulant, strength of coagulant, $\mathrm{pH}$, time and temperature of coagulation and straining method may affect the physical quality of the chhana (Jonkman and Das, 1993).

Moreover, chhana from cow and buffalo milk had acceptable flavor where as, that from goat's milk was slightly acidic. While the chhana made from cow milk had higher moisture than the chhana from buffalo milk. Whereas the quality of chhana did not vary significantly with different coagulants, for example, chhana produced with lactic acid and citric acid has given the soft body or with lemon juice resulted in slightly hard body (Sahu, 2007). It has been found that the production of chhana in desirable quality from buffalo milk was produced with modified processing parameters, for example, the chhana blended with cream has perceived the mild acidic flavour, soft body and smooth texture and suitable for manufacture of spreads or spreads with desirable spread ability at refrigeration temperature and of high nutritional quality by using functional ingredients (Chappalwar et al., 2010). Since chhana is one of the base materials for production of a variety of milk products like Paneer, Rasogolla, Sandesh and Gulabjaman in Asian countries, has not been well studied in the Province of Sindh or even in Pakistan; 
thus an approach was hypothesized to produce and evaluate the quality and yield of chhana by using two different milk sources (milk of cow \& buffalo).

\section{Materials and Methods}

Milk: Milk (cow or buffalo) obtained from Livestock Experiment Station, Faculty of Animal Husbandry and Veterinary Sciences, Sindh Agriculture University Tandojam, was used during the production of chhana.

Coagulant: Food grade citric acid, acetic acid and/or lactic acid were used to coagulate the milk during chhanamaking.

pH meter: $\mathrm{pH}$ meter (Model HI, Hanna Instruments, Italy) was used to determine the $\mathrm{pH}$ value of chhana sample.

\section{Methods}

Whole milk of cow or buffalo was collected in clean milk cans and brought to Dairy Products and Processing Laboratory, Department of Animal Products Technology, Faculty of Animal Husbandry and Veterinary Sciences, Sindh Agriculture University, Tandojam. After receiving of milk, it was first strained through muslin cloth and sample $(250 \mathrm{ml})$ was taken for analysis purpose, while rest of the milk was processed for chhana-making.

Experiment was arranged in a Randomized complete block (RCB) design with $2 \times 3$ factorial treatment combinations of two milk sources i.e. cow milk (CM) and buffalo milk (BM) and three coagulants i.e. citric acid (CA), lactic acid (LA) and acetic acid (AA). In each experiment six batches were prepared according to the method as reported by Chappalwar et al., (2010), and replicated four times as per following treatment combinations.

Milk of cow or buffalo was heated to its boiling point $\left(100.15^{\circ} \mathrm{C}\right)$ in large pan and allowed to cool at $70^{\circ} \mathrm{C}$ under running tap water. It was then added a coagulant i.e. (CA, LA or AA, $0.5 \%$ ) and stirred slowly until complete coagulation occurred. The coagulated mass was kept undisturbed for $2 \mathrm{~min}$ and than transferred to muslin cloth for drainage of whey without applying pressure to obtained chhana.

\section{Physical Analysis of Chhana}

Titratable acidity (TA): Acidity percentage was determined according to the method of Association of Official Analytical Chemists (AOAC, 2000). Chhana sample $(10 \mathrm{~g})$ was taken in a beaker, and distilled water (8ml) was added for dilution. Diluted chhana sample was filtered through filter paper and filtered chhana sample (9ml) was titrated with $\mathrm{N} / 10 \mathrm{NaOH}$ solution using titration kit, where phenolphthalein (4 drops) was used as an indicator. The volume of alkali used was noted and calculation was made using following formula:

$$
\mathrm{TA}(\%)=\frac{\text { Quantity of } \mathrm{N} / 10 \mathrm{NaOH} \text { used } \times 0.009}{\text { Volume of sample taken }} \times 100
$$

pH values: $\mathrm{pH}$ value of chhana was determined by using pH meter (Model HI, Hanna Instrument, Italy).

\section{Sensory Analysis}

Sensory analysis of chhana (Cow and/or Buffalo milk) was performed according the method as reported by Chappalwar et al. (2010). A panel of seven judges was drawn from the students of Animal Products Technology. They were first familiarized with sensory attributes of chhana and thereafter, the samples were served for evaluation. Nine-point hedonic scale with one for "dislike extremely" and nine for "like extremely" was used to observe the significant difference between the samples.

Statistical Analysis

The data so obtained was edited, tabulated and analysed according to statistical procedures like descriptive statistics and analysis of variance (ANOVA). In case of significant differences exists, the means were further computed using least significant difference (LSD) at $5 \%$ level of probability through computerized statistical package i.e. Student Edition of Statistix (SXW), Version 8.1 (Copyright 2005 Analytical Software, U.S.A).

\section{Results}

Effect of Milk Source and Coagulant on The Acceptability (Score) of Chhana.

Chhana, a coagulated milk product was prepared from cow and /or buffalo milk with different concentrations of coagulants, and it was served to panel of seven Judges for acceptance. The score so obtained was analysed, and results are depicted in Table 1 . The results indicate that there is no any significant differences $(\mathrm{P}>0.05)$ among all the chhana products except cow milk chhana coagulated with acidulants $(1 \%)$. Cow milk chhana coagulated with acetic acid $(1 \%)$ perceived significantly $(\mathrm{P}<0.05)$ better score (6.43) compared to that of coagulated with citric acid (1\%) (5.29 score), and lactic acid (1\%) (4.71 score). Similarly, there were no any significant differences (P>0.05) between the chhana prepared from the cow milk or buffalo milk coagulated with similar concentration of coagulant (i.e. $0.5,1.0,2.0$ or $4.00 \%$ ). However, cow milk coagulated with different concentration of coagulant showed significantly highest score $(6.38$, score) for $0.5 \%$ concentration of coagulant compared to that of coagulated with $2.0 \%$ or $4.00 \%$ (i.e. 4.86 or 3.10 score, respectively). While in of buffalo milk chhana similar scoring trend was observed as found in cow milk chhana i.e. 6.29 score for $0.5 \%$ coagulant followed by 5.24 score for $1 \%$ coagulant, 4.57 score for $2 \%$ coagulant and 3.57 score for $4 \%$ coagulant (Table 1).

\section{Influence of Milk Source on Physical Characteristics} of Chhana:

Titratable acidity: It was observed (Table 2) that there was significant influence of milk source on titratable acidity of chhana product. Acidity in cow milk chhana prepared with either acetic acid or lactic acid was significantly $(\mathrm{P}<0.05)$ higher (i.e. $0.16 \pm 0.001$ or $0.15 \pm 0.002 \%$, respectively) compared to that of buffalo milk chhana (i.e. $0.14 \pm 0.001$ or $0.14 \pm 0.001 \%$, respectively). The differences among the acidity of chhana prepared from cow and buffalo milk coagulated with citric acid (i.e. $0.16 \pm 0.004 \%$ and $0.16 \pm 0.004 \%$, respectively) were statistically non significant $(\mathrm{P}>0.05)$. 
The overall mean acidity of cow milk chhana $(0.16 \pm 0.001 \%)$ prepared with different coagulant was comparatively higher $(\mathrm{P}<0.05)$ from that of buffalo milk chhana $(0.15 \pm 0.001 \%)$. It was further observed that there was significant influence of coagulant on acidity of chhana. Chhana prepared with citric acid showed significantly higher $(\mathrm{P}<0.05)$ acidity $(0.16 \pm 0.001)$ compared to prepared with acetic acid $(0.15 \pm 0.001 \%)$ or with lactic acid $(0.15 \pm 0.001 \%)$, While there were no any significant $(\mathrm{P}>0.05)$ variation among chhana prepared with acetic acid and lactic acid.

Table 1 Effect of various coagulants on the acceptability (score) of chhana prepared from cow and buffalo milk.

\begin{tabular}{|c|c|c|c|}
\hline \multirow[b]{2}{*}{$\begin{array}{l}\text { Coagulant } \\
\text { Type }\end{array}$} & \multicolumn{3}{|c|}{ Chhana } \\
\hline & $\begin{array}{c}\text { Concentra } \\
\text { tion }(\%)\end{array}$ & $\begin{array}{l}\text { Cow milk } \\
\text { (score) }\end{array}$ & $\begin{array}{c}\text { Buffalo milk } \\
\text { (score) }\end{array}$ \\
\hline \multirow{4}{*}{ Acetic acid } & 0.5 & $6.71^{\mathrm{ab}}$ & $6.00^{\text {abcd }}$ \\
\hline & 1.0 & $6.43^{\mathrm{abc}}$ & $5.43^{\text {cdef }}$ \\
\hline & 2.0 & $5.29^{\mathrm{cdef}}$ & $4.57^{\text {efgh }}$ \\
\hline & 4.0 & $3.57^{\text {hij }}$ & $3.57^{\text {hij }}$ \\
\hline \multirow{4}{*}{ Citric acid } & 0.5 & $5.57^{\text {bcde }}$ & $6.00^{\mathrm{abcd}}$ \\
\hline & 1.0 & $5.29^{\text {cdef }}$ & $4.86^{\text {defg }}$ \\
\hline & 2.0 & $4.29^{\text {fghi }}$ & $4.57^{\text {efgh }}$ \\
\hline & 4.0 & $3.14^{\mathrm{ij}}$ & $3.86^{\text {ghi }}$ \\
\hline \multirow{4}{*}{ Lactic acid } & 0.5 & $6.86^{\mathrm{a}}$ & $6.85^{\mathrm{a}}$ \\
\hline & 1.0 & $4.71^{\mathrm{efgh}}$ & $5.43^{\text {cdef }}$ \\
\hline & 2.0 & $5.00^{\text {defg }}$ & $4.57^{\text {efgh }}$ \\
\hline & 4.0 & $2.57^{\mathrm{j}}$ & $3.29^{\mathrm{ij}}$ \\
\hline
\end{tabular}

Means with similar superscript within the same row or column are not significantly different.

Table 2 Titratable acidity (\%) in chhana prepared from cow and buffalo milk

\begin{tabular}{|c|c|c|c|}
\hline \multirow{2}{*}{$\begin{array}{c}\text { Coagulant } \\
(0.5 \%)\end{array}$} & \multicolumn{2}{|c|}{ Source of milk (Mean \pm SE \%)* } & \multirow{2}{*}{$\begin{array}{c}\text { Mean } \pm \mathrm{SE} \\
\% * *\end{array}$} \\
\hline & Cow & Buffalo & \\
\hline Acetic acid & $0.16 \pm 0.001^{\mathrm{ab}}$ & $0.14 \pm 0.001^{\mathrm{c}}$ & $0.15 \pm 0.001^{\mathrm{b}}$ \\
\hline Citric acid & $0.16 \pm 0.004^{\mathrm{ab}}$ & $0.16 \pm 0.004^{\mathrm{a}}$ & $0.16 \pm 0.001^{\mathrm{a}}$ \\
\hline Lactic acid & $0.15 \pm 0.002^{\mathrm{b}}$ & $0.14 \pm 0.001^{\mathrm{c}}$ & $0.15 \pm 0.001^{\mathrm{b}}$ \\
\hline Mean \pm SE & $0.16 \pm 0.001^{\mathrm{a}}$ & $0.15 \pm 0.001^{\mathrm{b}}$ & $0.16 \pm 0.001$ \\
\hline
\end{tabular}

$* \operatorname{LSD}(0.05)=0.008 \pm 0.004$ Means with similar superscript within the same row or column are not significantly different. ** LSD $(0.05)=$ $0.004 \pm 0.002$ Means with similar superscript within the same column are not significantly different.

Table $3 \mathrm{pH}$ (values) in chhana prepared from cow and buffalo milk

\begin{tabular}{|c|c|c|c|}
\hline \multirow{2}{*}{$\begin{array}{c}\text { Coagulant } \\
(0.5 \%)\end{array}$} & \multicolumn{2}{|c|}{ Source of milk (Mean \pm SE \%)* } & \multirow{2}{*}{$\begin{array}{c}\text { Mean } \pm \mathrm{SE} \\
\% * *\end{array}$} \\
\hline & Cow & Buffalo & \\
\hline Acetic acid & $0.16 \pm 0.001^{\mathrm{ab}}$ & $0.14 \pm 0.001^{\mathrm{c}}$ & $0.15 \pm 0.001^{\mathrm{b}}$ \\
\hline Citric acid & $0.16 \pm 0.004^{\mathrm{ab}}$ & $0.16 \pm 0.004^{\mathrm{a}}$ & $0.16 \pm 0.001^{\mathrm{a}}$ \\
\hline Lactic acid & $0.15 \pm 0.002^{\mathrm{b}}$ & $0.14 \pm 0.001^{\mathrm{c}}$ & $0.15 \pm 0.001^{\mathrm{b}}$ \\
\hline Mean $\pm \mathrm{SE}$ & $0.16 \pm 0.001^{\mathrm{a}}$ & $0.15 \pm 0.001^{\mathrm{b}}$ & $0.16 \pm 0.001$ \\
\hline
\end{tabular}

$p H$ (values): It was observed (Table 3 ) that there was significant $(\mathrm{P}<0.05)$ influence of milk source on $\mathrm{pH}$ values of chhana prepared from cow milk with either acetic acid or citric acid (i.e $5.65 \pm 0.01$ or $5.52 \pm 0.02$, respectively) compared to that of buffalo milk chhana (i.e.
$5.45 \pm 0.01$ or $5.45 \pm 0.01$, respectively). Regardless, $\mathrm{pH}$ value varied among the chhana prepared from cow and buffalo milk coagulated with lactic acid $(5.55 \pm 0.001$ and $5.53 \pm 0.02$, respectively), the differences were statistically non-significant $(\mathrm{P}>0.05)$. The overall mean $\mathrm{pH}$ value of cow milk chhana $(5.58 \pm 0.005)$ prepared with different coagulant was comparatively higher $(\mathrm{P}<0.05)$ from that of buffalo milk chhana (5.47 \pm 0.02$)$. It was further observed that there was significant influence of coagulants on $\mathrm{pH}$ value of chhana. Chhana prepared with acetic acid showed significantly $(\mathrm{P}<0.05)$ higher $\mathrm{pH}$ value (5.55 \pm 0.001$)$ compared to that of prepared with lactic acid $(5.54 \pm 0.004)$ while there were no any significant $(\mathrm{P}>0.05)$ variation among chhana prepared with citric acid $(5.49 \pm 0.01)$ and lactic acid (5.55 \pm 0.001$)$.

\section{Influence of Milk Source on Chemical Characteristics of Chhana.}

It has been observed from preliminary studies that cow milk chhana prepared with different coagulants (i.e. citric acid, acetic acid and lactic acid) showed no significant variation among the chhana products. Further, among the different concentration level of coagulants $(0.5,1,2$ and $4 \%), 0.5$ and $1 \%$ level perceived the highest score. Thus in strategic studies, lower concentration i.e. $0.5 \%$ level of coagulant was included to observe the influence of milk source on chemical characteristics of chhana.

\section{Discussion}

Chhana is an important traditional milk product used to be a base material for the preparation of variety of sweets i.e Rasgula, sendish, rasmalai, chhana-cham, chhana-murki (Jindal and Grandison, 2001). It has been reported that the factors like type of milk, heat treatment, coagulation temperature, acidity of milk-acid mixture and straining methods might be responsible for qualitative variability of chhana (Jonkman and Das, 1993). In the present study, influence of milk source on physical characteristics has been evaluated. Two milk sources (i.e. cow milk and buffalo milk) and three coagulants (i.e citric acid, lactic acid and acetic acid) were used during the study period. Preliminary the chhana was prepared from each of cow and buffalo milk coagulated with citric acid, acetic acid, and/or lactic acid each at 0.5, 1, 2 and 4\% concentration level and among each coagulant, the chhana made with $0.5 \%$ concentration level of coagulants rated better acceptability score. Similar coagulants (i.e lactic acid and citric acid) and milk source were used in a study conducted by Sahu and Das (2009). Similarly, better textural characteristics of chhana prepared with $0.5 \%$ concentration level, each of citric acid and lactic acid among five concentration levels $(0.5,1.0,2.0,4$ and 8\%) were reported by Mahuya et al. (2005). While among three concentration levels of citric acid (2, 3, and 5\%), 2\% level has been suggested to be better coagulant for chhana/paneer with most desirable characteristics by Shahnawaz et al. (2011). Moreover, the temperature of heating and coagulant had reported to be a significant influence on chemical composition of chhana (Jindal and Grandison, 2001). In this regard in the present study physical characteristics such as titratable acidity and $\mathrm{pH}$ 
values acceptability analysis of chhana prepared with $0.5 \%$ level of each of citric acid, acetic acid and lactic acid were examined. It was noticed that milk source (cow or buffalo) had significant $(\mathrm{P}<0.05)$ influence on the titratable acidity of chhana prepared either with acetic acid or lactic acid, while with citric acid the influence of milk source was not countable $(\mathrm{P}>0.05)$. Present findings regarding acidity of chhana are relatively inline with that of reported by Shelke et al. (2002). A remarkable $(\mathrm{P}<0.05)$ influence of milk source was observed in $\mathrm{pH}$ values of chhana prepared either with acetic acid or with citric acid but not with lactic acid $(\mathrm{P}>0.05)$. Present findings suggest that this influence on $\mathrm{pH}$ values could be of due to type of coagulants as interactive effect of coagulants has been observed in a study conducted by Mahuya et al. (2005). Moreover, the overall mean $\mathrm{pH}$ value of cow milk chhana was comparatively $(\mathrm{P}<0.05)$ higher than that of buffalo milk chhana. This could probably be attributed with the influence of type of milk. Similar findings of $\mathrm{pH}$ values were reported in a study conducted by Anon et al. (1993), Jindal and Grandison (2001).

\section{References}

Anon. 1993. How to make chhana and sandesh, Food-Chain (9): 15.

AOAC. 2000. Dairy products. In: Official Methods of Analysis. Association of Official Analytical Chemists Inc. Gaithersburg, U.S.A.

Chappalwar AM, Raziuddin H, Zanjad PN. 2008. Process optimization for preparation of buffalo milk chhana spread. Collage of Veterinary and Animal Sci. India. 12(4): 402431.
Chappalwar AM, Zanjad PNV, Pawar D, Machewad GM. 2010. An investigation of varying composition and processing conditions on the organoleptic properties of chhana spread. Int. J. of Dairy Technol., 63 (3):445-450.

De S. 1980. Outline of Dairy Technol, Dehli: Oxford University Press.

Jindal AR, Grandison S. 2001. The preperation of chhana from cow and buffalo milk. Int. J. of Food Sci. Technol. 32:511517.

Jonkman MJ, Das H. 1993. Optimization of process parameters for production of chhana from low fat cow milk. J. of Food Sci. Technol., 30:417-421.

Mahuya BR, Chakraborty K, Raychaudhuri U. 2005. The effect of coagulants on the texture of chhana an acid and heat coagulated product made from milk. Int. J. of Food Sci. and Technol. India., 40(2): 799-810

Sahu JK. 2007. Development of process and machinery production of chhana in dairy Tech: India Dairy products. Unpublished PhD Thesis, IIT India.

Sahu JK, Das H. 2009. A continuous heat-acid coagulation unit for continuous production of chhana. J. of Sci. and Technol., 4(11): 40-45.

Sahu JK, Das H. 2010. Effect of heating and cooling rates on recovery of milk components during heat-acid coagulation of milk for preparation of chhana an Indian soft cottage cheese. Int. J. of Food. Sci. India., (3): 163-172.

Shahnawaz UK, Ashraf MP, Sarfaraz AV, Salahuddin M. 2011. Effect of different coagulants at varying strengths on the quality of paneer made from reconstituted milk. J. of Food Sci. Technol. India. 22 Agust.

Shelke RR, Khedkar CD, Pandey SP. 2002. Effect of acid value of chhana on the quality of rasogolla. J. of Dairy Sci. India. 55(1): 51-53. 